\title{
The Effectiveness of Structured Teaching Programme on Knowledge Regarding ICDS Programme among Mothers of under Five Children
}

\author{
Kavita Betageri ${ }^{1}$, Sunita Tata $^{2}$ \\ ${ }^{1}$ Msc $2^{\text {nd }}$ year, Department of Child Health Nursing, Krishna Institute of Nursing Science, KIMSDU, Dhebewadi Road, Malkapur-415539, \\ Karad (Maharashtra) India. \\ ${ }^{2}$ Associate professor, Department of Child Health Nursing, Krishna Institute of Nursing Science, KIMSDU, Dhebewadi Road, Malkapur- \\ 415539, Karad (Maharashtra) India
}

\begin{abstract}
During 1975, the Maternal Mortality Rates and Infant Mortality Rates were extremely high due to severe drought the country faced. To stop the soaring rate of MMR and IMR, the Prime Minister Smt. Indira Gandhi, launched ICDS in a few places which were affected acutely by drought. Purpose: To study The Effectiveness Of Structures Teaching Programme On Knowledge Regarding Integrated Child Development Services Programme Among Mothers Of Under Five Children. Methodology: An evaluative research study conducted on $\mathbf{6 0}$ mothers of fewer than five children in Anganwadis by non probability convenient sampling. Knowledge of mothers regarding ICDS was assessed by administering structured knowledge questionnaires. Data collection tools included, Demographic variables of the mothers, structured knowledge questionnaires regarding ICDS programme. Result: The Mean, Standard deviation of total knowledge scores of mothers regarding ICDS programme revealed that the pre test mean knowledge score \& standard deviation of the mothers was $14.3 \quad 1.78$, which was increased in post test to 23.32 .03 . Obtained pre \& post test scores paired ' $t$ ' value is 38.684 \& $p$ value is $<0.0001$ which is considered extremely significant, indicates significant improvement in knowledge of mothers. Conclusion: Structured Teaching Programme regarding ICDS programme was an effective method for providing adequate knowledge and helped mothers to enhance their knowledge \& utilization of services provided under ICDS programme.
\end{abstract}

Keywords: ICDS, Knowledge, Mother's of under five children, Effectiveness, Structured Teaching Programme

\section{Introduction}

Children are the first call on agenda of human resource development and the foundation for lifelong learning and human development is laid in these crucial early years, it is now globally acknowledged that investment in human resources development is a pre-requisite for economic development of any nation. ${ }^{1}$

The ICDS was initiated in 1975 following the adoption of the National Policy for Children and was planned to be preventive and promotive measures. It was stated in the National Policy on Children, before birth and after birth and through the period of growth, to ensure their full physical, mental and social development. The state shall progressively increase the scope of such services so that, within a reasonable time, all children in the country enjoy optimum conditions for balanced growth. ${ }^{2}$

The objectives of ICDS are to improve the nutritional and health status of the children in the age group of 0-6 years, to lay the foundation for proper psychological, physical and social development of the child, to reduce the incidence of mortality, morbidity, malnutrition and school dropout, to achieve effective co-ordination of policy and implementation amongst the various departments to promote child development and to enhance the capability of the mother to look after the normal health and nutritional needs of the child through proper health education and nutrition. ${ }^{3}$

\section{Review of Literature}

1) A study conducted by Selvakumari S, To assess the effectiveness of structured teaching programme on knowledge regarding optional vaccines among mothers of under five children in Kovilpalayam at Coimbatore. The sample for this study consisted for 40 mothers selected by convenience sampling technique. A structured interview schedule was used to assess the knowledge among mothers of under five children. Result shows that 40 samples 40 samples were enrolled in the study. Inferential statistics were used to analyze the date. The obtained' $t$ ' value for knowledge was 18.91 at (P 0.05). The results indicated that the knowledge regarding optional vaccine among mothers with under five children was significantly improved after education. ${ }^{4}$

2) A study conducted by Madhavi M, to assess the change of knowledge and practices of mothers of under five children, after community health worker training and practice of integrated management of childhood illness, at rural areas of Primary Health Centre of Telangaon and Khabarrangana in Warda District, Maharashtra, India. The study included 640 mothers of under five children.Primary health centre workers provides diarrhoea management training to mothers of under five children, after training mothers gained knowledge and skills regarding diarrhoea management for under five children. The results showed that there was significant improvement from pre test assessment to post test assessment score (42\% to $90.5 \%){ }^{5}$

3) A study conducted by Gupta S, Kumar D to assess the impact of nutrition advice given to mothers of under five children. Simple random sampling was used and a total 


\section{International Journal of Science and Research (IJSR) \\ ISSN (Online): 2319-7064 \\ Index Copernicus Value (2013): 6.14 | Impact Factor (2015): 6.391}

of 206 under five children (134 males and 72 females) enrolled for the study by house to house visit. 43 children having varying degrees of malnutrition as per IAP criteria were followed longitudinally for a period of one year through monthly home visits. Episodes of illness and weight was recorded every month and plotted on growth chart. The result was the prevalence of malnutrition was $28.87 \%$. Majority were having Grade I Malnutrition. Post intervention results revealed that nutrition education in mothers had a positive effect on the nutritional status of their children.

\section{Methodology}

An evaluative study with one group pre -test -post -test design was undertaken after institutional ethical committee approval to assess the effectiveness Structured Teaching Programme on knowledge regarding ICDS programme among mothers of under five children. The sample size was 60. The samples were selected from the Anganwadis of Karad. The duration of study was 1 month.

\section{Inclusion Criteria}

1. Mothers who are between the age group of 20-40 years.

2. Mothers who are available at the time of study.

3. Mothers who are having children below 5 years

\section{Exclusion Criteria}

1. Mothers with unsoundness of mind.

2. Mothers who are not available at the time of study.

\section{Description of the Tool}

Section I : Demographic profile. The characteristics include Age, educational status, occupation of the mother, monthly income of the family, source of information regarding ICDS, number of children, type of family.

Section II: Structured Knowledge Questionnaire It Consists Of 15 Items In Multiple Choice Question Form And It Is Divided Into Part-I, Part-II, Part-III, Part- IV To Assess The Knowledge Of Mothers.

10 Items In Dichotomous Form To Assess The Knowledge Of Mothers Of Under Five Children Regarding Integrated Child Development Services.

\section{Results}

\section{Section I: Demographic profile of Mother}

Among 60 mothers, majority 29(48.3\%) mothers belong to the age group of 20-25 years, and Majority of mothers 22(36.7\%) educational status was primary, Maximum of mothers occupation were 36(60\%) house wife, Majority of mothers 34(56.7\%) monthly income were Rs 5001-10000, Majority of mothers 31(\%) were having no any information regarding ICDS programme, Majority of mothers 20(33.3\%) got information from health professionals, Majority of mothers 20(33.3\%) got information from health professionals, Maximum of mothers 40(66.7\%) belong to nuclear family Majority of mothers 31(51.7\%) having 2 children.
Section II: Table no- 1 Distribution of frequency and percentage of pre test and post test knowledge scores of mother's of under five children regarding ICDS programme, $\mathrm{n}=60$

\begin{tabular}{|c|c|c|c|c|c|}
\hline \multirow{2}{*}{$\begin{array}{c}\text { Level of } \\
\text { knowledge }\end{array}$} & \multirow{2}{*}{ Score } & \multicolumn{2}{|c|}{ Pre Test } & \multicolumn{2}{c|}{ Post Test } \\
\cline { 3 - 6 } & & frequency & Percentage & frequency & Percentage \\
\hline Poor & $0-10$ & 1 & 1.67 & 0 & 0.00 \\
\hline Average & $11-18$ & 58 & 96.67 & 7 & 11.67 \\
\hline Good & $19-25$ & 1 & 1.67 & 53 & 88.33 \\
\hline \multicolumn{2}{|c|}{ Total } & 60 & 100 & 60 & 100 \\
\hline
\end{tabular}

The above table shows the comparison of pre test and posttest knowledge of mothers of regarding Integrated Child Development Services. The pre-test table depicts that majority of mothers of under five children residing at Karad $58(96.67 \%)$ had average level of knowledge about Integrated Child Development Services, whereas only $1(1.67 \%)$ of mothers of under five children had poor and Good level of knowledge regarding Integrated Child Development Services before administration of structured teaching programme.

The post-test table depicts that, majority of mothers of under five children residing at Karad 53(88.33\%) had good level of knowledge about Integrated Child Development Services whereas $7(11.67 \%)$ of mothers of under five children had Average level of knowledge and no mothers of under five children residing at had poor knowledge regarding Integrated Child Development Services after administration of structured teaching program.

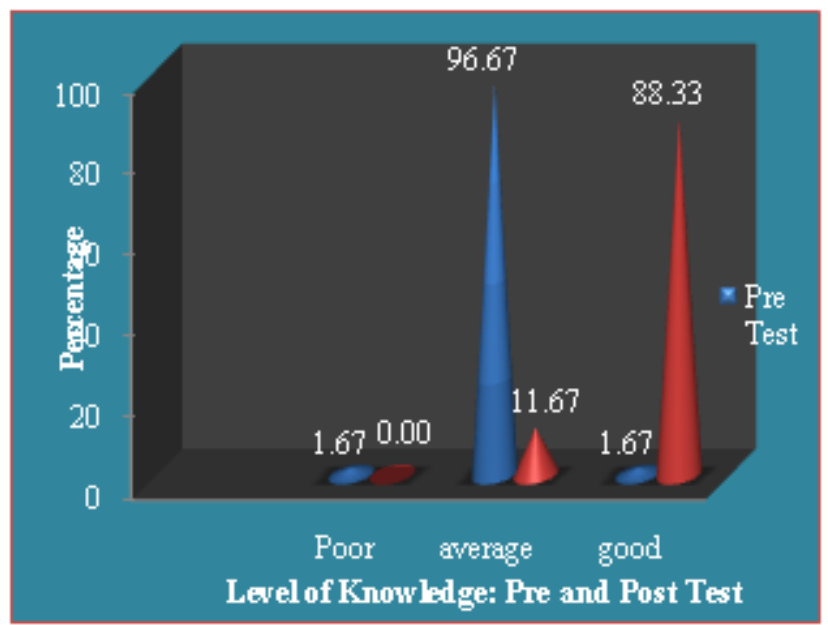

Figure 1: Graph showing comparison of knowledge scores of mother's of under five children regarding ICDS programme

Table 2: Mean, Median and Standard Deviation of knowledge scores of mother's of under five children regarding ICDS programme, $\mathbf{n}=\mathbf{6 0}$

\begin{tabular}{|c|c|c|c|}
\hline Area of analysis & mean & median & Standard deviation \\
\hline Pre test & 14.3 & 15 & 1.78 \\
\hline Post test & 23.3 & 24 & 2.03 \\
\hline Difference & 9.0 & 9.0 & 1.75 \\
\hline
\end{tabular}

Paired ' $t$ ' value is $38.684, p<0.0001$

The above table shows that knowledge score regarding ICDS programme before and after structured teaching programme of 60 observations with difference mean of 9.0 


\section{International Journal of Science and Research (IJSR) \\ ISSN (Online): 2319-7064 \\ Index Copernicus Value (2013): 6.14 | Impact Factor (2015): 6.391}

and standard deviation of 1.75. The computed ' $t$ ' test statistic value is 38.684 . since the $p$ value for the test is less than 0.05 , the null hypothesis is rejected at the $95 \%$ confidence level. It shows that the Structured Teaching Programme is effective method for improving the knowledge of mothers regarding ICDS programme.

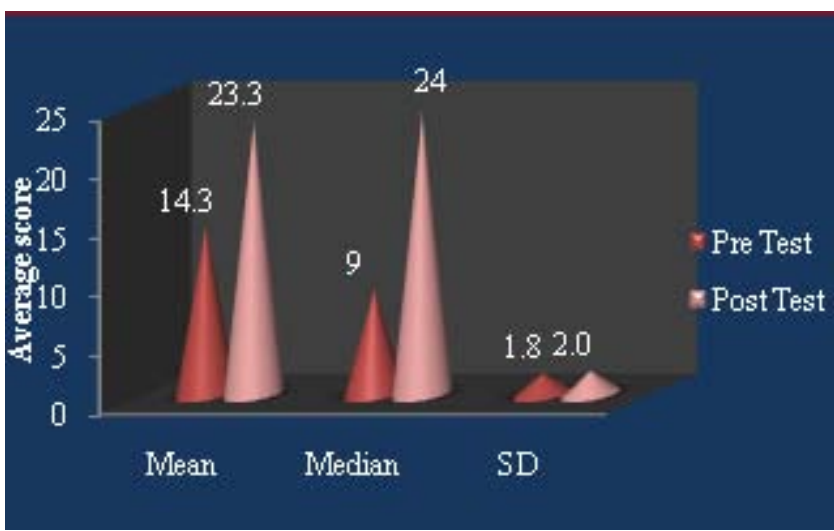

Figure 2: Graph showing the Mean, Median and Standard Deviation of Pre and Post test knowledge score of mother's

\section{Discussion}

The findings of present study have been discussed with reference to the objectives and hypothesis. A findings of the study shows that there was significant difference between the pre-test and post-test knowledge level of mothers of under five children residing at Karad regarding Integrated Child Development Services. The mean knowledge score of 60 mothers in pre-test was $14.3 \%$ where as it had increased up to $23.3 \%$ during the post-test as an effectiveness of structured teaching programme. Therefore the difference assessed was $9.0 \%$ between pre-test and posttest. Hence on-going teaching and health education programs can further improve the knowledge of mothers of under five children residing at Karad.

Supporting studies show results compatible with the findings of our Study was conducted by Lal S, Khanna P, Kumar S et $\mathbf{a l}^{7}$ The study concluded that nutrition and health education programme given was very effective to increase the awareness among mothers.

\section{Conclusion}

The study concluded that the Structured Teaching Programme regarding ICDS programme was an effective method for providing adequate knowledge and helped mothers to enhance their knowledge \& utilization of services provided under ICDS programme.

\section{Future Scope}

A similar study can be conducted on larger sample for the purpose of generalization. A descriptive study can be conducted to assess the effectiveness of the structured teaching program based on mother"s knowledge. The study can be conducted related to assessment of knowledge, attitude and practices of mothers on Integrated Child Development Services program. Comparative study can be conducted in ICDS and Non ICDS blocks to assess the health status of children.

\section{Acknowledgement}

The Author is thankful to administrative authority of Krishna Institute of Nursing Science and Krishna Hospital, Karad, Head of Department of Paediatrics Doctor Aundhakar Sir and Dr.Ingale Sir for their guidance cooperation and support .

\section{References}

[1] CentrallySponsoredScheme, [homepageontheInterrnet].2011[cited2012Oct16].Availa ble

from:http://nuapada.nic.in/centrally\%20sponsored\%20sc hemes. asp

[2] NATIONAL RESPONSE TO NUTRITION PROBLEMS, [monograph on the Internet]. Nodate[cited2012Dec29].Availablefrom:http// wcd.nic.in/../ 9.Natio nal \% \%20response\%20to\%20nutrition\%

[3] Integrated Child Development Services (ICDS) Scheme, [homepage on the Internet]. 2009 [cited 2011 Nov 18]. Available from: http://wcd.nic. in/icds.htm

[4] Selvakumari S. Knowledge of Optional Vaccines Among Mothers of "Under Five Children". Journal of Management and Science [serial on the Internet]. 2011;(1) Available from: Manipal University, Manipal College of Nursing Web site: http://www.doaj.org/doaj?func=abstract\&id=1109070

[5] Madhavi M.an Impact on reducing under five children morbidities at community level using IMNCI guidelines. [homepage on the Internet]. No date Available from: Obafemi Awolowo University, Department of community health Web site: www.bmj.com/content/344/bmj.e1634

[6] Gupta S, Kumar. An Intervention study in Malnutrition among Under Five Children in a Rural Area of Jammu, JK Science [Journal article]. No date

[7] [cited 2013 Dec 4]. Available

[8] from:http://www.jkscience.org/archives/volume145/Artic le4.pdf

[9] Lal S, Khanna p, Kumar S. Participation of pregnant and lactating mothers in ICDS programme in rural area. Indian Journal of Maternal and Child Health. [serial on the Internet]. 1995 [cited 2012 Sep 18].;6(3) Available from www.ncbi.nlm.gov/pubmed/12346502

\section{Author Profile}

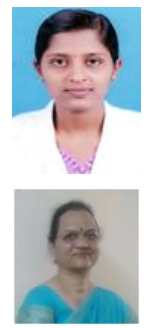

Kavita S Betageri, $2^{\text {nd }}$ year Msc(n) Student, Krishna Institute of Nursing Sciences, Karad. KIMSDU, Maharashtra, India

Dr. Sunita . H. Tata is B.A.(Hon's)R.N.R.M, Msc, Child Health Nursing) PhD, Associate Professor \&Nursing Director Krishna Hospital, Karad, Maharashtra, India 